\title{
Bioaccessibility and antioxidant activities of finger millet food phenolics
}

\begin{abstract}
Disna Kumari ${ }^{\mathrm{a}}$, Anoma Chandrasekara ${ }^{\mathrm{a}^{*}}$ and Fereidoon Shahidi ${ }^{\mathrm{b}}$
aDepartment of Applied Nutrition, Wayamba University of Sri Lanka, Makandura, Gonawila, 60170, Sri Lanka

bepartment of Biochemistry, Memorial University of Newfoundland, St. John's, NL, Canada, A1B 3X9

*Corresponding author: Anoma Chandrasekara, Department of Applied Nutrition, Wayamba University of Sri Lanka, Makandura, Gonawila, 60170, Sri Lanka. Tel: +94 (31) 2298120; E-mail: anomac@wyb.ac.lk

DOI: $10.31665 /$ JFB.2019.6187

Received: February 19, 2019; Revised received \& accepted: March 10, 2019

Citation: Kumari, D., Chandrasekara, A., and Shahidi, F. (2019). Bioaccessibility and antioxidant activities of finger millet food phenolics. J. Food Bioact. 6: 100-109.

Abstract

Finger millet flour was used to prepare five different foods using steaming, pressure cooking, dry roasting and open boiling as representative preparation methods. The soluble and bound phenolics of freeze dried foods were extracted. The gastric and intestinal bioaccessibility and potential absorption of phenolic compounds of foods were determined accommodating a simulated in vitro digestion model. The phenolic extracts of foods and supernatants collected at different stages of in vitro digestion were examined for their phenolic contents and antioxidant activities. The content of ferulic acid, of phenolic extracts of foods were determined using high performance liquid chromatography (HPLC). The open pan boiling retained higher content of phenolics and showed higher antioxidant activities compared to other food preparations. The release of phenolic compounds increased stepwise from gastric to intestinal phase for all foods and the bioaccessibility and potential absorption of phenolic compounds depended on the food preparation methods.
\end{abstract}

Keywords: Colonic fermentation; Cooking methods; Dynamic in vitro digestion; Retentate.

\section{Introduction}

The development of non-communicable diseases (NCDs) has increased steadily worldwide and is becoming a leading cause of death. Epidemiological studies have demonstrated that unhealthy dietary behaviour and sedentary lifestyle predominantly contribute to the occurrence of NCDs (Meyer et al., 2000). Evidences established from previous studies show that the consumption of whole grains and their products contribute to the reduction of a number of NCDs such as cardiovascular disease, stroke, diabetes and certain types of cancers associated with oxidative stress (McKeown, 2002). Millets are a group of cereals with small grain size and possess varied level of phenolics and antioxidant activities depending on the variety and location of production (Kumari et al., 2017).

The unique phytochemical composition of millet grains complements those in other plant foods such as legumes, fruits and vegetables when consumed together. Finger millets are rich sources of flavonoids and phenolic acids (Chandrasekara and Shahidi, 2011). Both free and conjugated forms of phenolic acids, which include derivatives of hydroxybenzoic and hydroxycinnamic acids are found in finger millets. The most abundant hydroxybenzoic acid and hydroxycinnamic acid in finger millets include protocatechuic and trans-ferulic, respectively (Shahidi and Chandrasekara, 2013). Furthermore, a number of flavonoids, such as anthocynidins, flavanols, flavones, flavanones, chalcones, and aminophenolic compounds have been reported (Chandrasekara and Shahidi, 2011; Shahidi and Chandrasekara, 2013). The total content of flavonoids in the free form is reported to be approximately $2 \mathrm{mg}$ per $\mathrm{g}$ of defatted meal of finger millets (Chandrasekara and Shahidi, 2011). Therefore, incorporation of millet grain flour in food preparations provides a better phenolic profile in the diet compared to those containing cereals such as rice and wheat alone. From a human nutrition perspective this is beneficial particularly for populations that consume less fruits and vegetables than the daily suggested servings. Fruits and vegeta- 
bles are major sources of flavonoids in the human diet.

Among millet grains, finger millet (Eluesine coracana) is widely used in the African continent and the Indian sub-continent. The flour is used to prepare steamed foods (Halape and Pittu), nonfermented flat breads, as well as thin and thick porridges, among others. These different food preparations generally employ different cooking methods. Previous studies have reported that processing change the content of phenolics of millets (Pradeep and Guha, 2011; Chandrasekara et al., 2012). However, there are limited published work on how different domestic food preparation methods affect the contents of phenolic compounds and the antioxidant activities of finger millet food. Further, the content of ferulic acid which is the most abundant hydroxycinnamic acid in finger millet grains has not been reported todate after preparation of different foods. Ferulic acid and its derivatives are potential agents for preventing and attenuating a number of conditions due to its hypoglycaemic, chemopreventive, hypotensive and antioxidative activities among others (Shahidi and Chandrasekara, 2010).

Health benefits of phenolic compounds in foods vary with the level of absorption and bioaccessibility. Potential absorption of a compound can be determined as the quantity that passes through the cell membranes in the intestine and is available for action within the cells. Bioaccessibility is referred to the amount of compound that is released from the solid food matrix into the gut (Shahidi and Peng, 2018). Phenolic compounds in foods are released to different degrees due to digestion in the gastric and intestinal phases (Chandrasekara and Shahidi, 2012; Minaxi et al., 2013). The residues after intestinal digestion enter the colon and undergo fermentation by the action of bacterial enzymes that facilitate the release of bound phenolics from the cell wall matrices. In the large intestine, free phenolic acids may exert their bioactivity locally or by bioconversion into colonic metabolites on the site of the epithelium. Stomach, intestinal lumen and the colon can retain substantial amounts of unabsorbed phenolic compounds from food, which may play a key role in protection of the gastrointestinal tract (GT) from oxidative stress and are associated with the reduction of the risk of gastric, colon and rectal cancers (Jenner et al., 2005).

To the best of our knowledge published reports on the bioaccessibility and bioavailability of phenolics of finger millet using different food preparation methods are non-existent. In this study we determined the phenolic contents and antioxidant activities of finger millet foods prepared using different preparation methods. Furthermore, the bioaccessibility, potential absorption and antioxidant activities of phenolics of finger millet foods subjected to in vitro dynamic digestion and colonic fermentation were determined.

\section{Materials and methods}

\subsection{Millet samples and chemicals}

A composite sample of whole grain finger millets (Eleusine coracana, variety 'Oshada') was used in this study. The samples used were grown at Mahailluppallama, Sri Lanka and were harvested in the crop year 2014.

\subsection{Chemicals}

Folin-Ciocalteu's reagent, linoleic acid, Tween 40 (polyoxyethylene sorbitan monopalmitate), sodium nitrite and calcium chloride, hydrochloric acid $(\mathrm{HCl})$, sodium bicarbonate, potassium chloride, and sodium sulphate were purchased from Research Lab Fine Chem Industries (Mumbai, India). 2,2-Diphenyl-1-picrylhydrazyl (DPPH), $\beta$-carotene, 2,2-azinobis(3-ethylbenzothiazoline-6-sulphonate diammonium salt) (ABTS), 2,2'-azobis-(2-methylpropionamidine) dihydrochloride (AAPH), ferrous chloride, sodium chloride, butylated hydroxyanisole (BHA), catechin, ferulic acid, trolox, diethyl ether, ethyl acetate, methanol, acetone, pepsin (from porcupine gastric mucosa), $\alpha$-amylase, pancreatin (from porcine pancreas), L-cysteine, activated charcoal, urea, ferrous sulphate, magnesium chloride, and zinc sulphate were purchased from Sigma-Aldrich Co, (St Louis, MO, USA). Sodium carbonate, ferric chloride, cobalt chloride, ammonium molybdate were purchased from Thomas Baker (Chemicals) Ltd (Bombay, India).

Aluminium chloride, trichloroacetic acid (TCA), and dibasic potassium phosphate were purchased from Techno Pharm Chem (Delhi, India). Sodium hydroxide $(\mathrm{NaOH})$, potassium phosphate monobasic, and potassium hydroxide were purchased from Loba Chem Pvt Ltd (India). Ferrozine (3-(2-pyridyl)-5,6-diphenyl1,2,4-triazine-4,4-disulphonic acid sodium salt) were purchased from SERVA Electrophoresis GmbH (Heildberg, Germany). Ethylenediaminetetraacetic acid tri sodium salt (Na3EDTA) was purchased from Needham Market (Suffolk, UK). Bile salt was purchased from Hi Media Laboratories Pvt Ltd (Mumbai, India).

\subsection{Preparation of finger millet foods, freeze drying and prepa- ration for analysis}

Finger millet flour $(100 \mathrm{~g})$ and fresh scraped coconut $(50 \mathrm{~g})$ were used as main raw ingredients for five food preparation methods employed in this work. Flat unfermented bread (Rotti), steamed foods, Pittu and Halape, a thick porridge (Thalapa) and a thin porridge were prepared following commonly used household procedures. Cleaned whole finger millet grains were dehulled using a rice polishing machine (Rice husker and polisher PM 500, Satake Engineering Co Ltd, Tokyo, Japan) and were ground (Phillips HR 2011, Koninklijke Phillips Electronics NV, Shanghai, China) to obtain a fine flour (sieve opening $0.038 \mathrm{~mm}$; As 200, Retsch, Haan, Germany).

Flat unfermented bread (Rotti) was prepared using finger millet flour, scraped coconut and $30 \mathrm{~mL}$ of water. In this, a wet paste was made with ingredients followed by roasting on a hot plate for 10 min. A steamed food, Pittu, was made mixing finger millet flour with scraped coconut and $15 \mathrm{~mL}$ of water into small granules followed by steaming for $15 \mathrm{~min}$. A steamed food (Halape) prepared with wet paste of finger millet flour, scraped coconut and $30 \mathrm{~mL}$ of water was wrapped in a leaf of Macaranga peltata and pressure cooked for $15 \mathrm{~min}$. A thick porridge (Thalapa) was prepared with finger millet flour by mixing with $50 \mathrm{~mL}$ of coconut milk extracted using $50 \mathrm{~g}$ of scraped. The mixture was boiled for 25 $\mathrm{min}$. A thin porridge was prepared using finger millet flour (100 $\mathrm{g})$, coconut milk $(50 \mathrm{~mL}$ extracted using $50 \mathrm{~g}$ of scraped coconut according to conventional procedure) and boiling water $(50 \mathrm{~mL})$ followed by boiling for $20 \mathrm{~min}$. Each food without adding coconut was prepared as controls. Foods were stored at $-80{ }^{\circ} \mathrm{C}$, after cooling to room temperature and were freeze dried at $-55^{\circ} \mathrm{C}$, and 0.012 mbar (Alpha 1-4 LD plus CHRIST, Osterode am Harz, Germany). The lyophilized samples were ground to pass through sieve opening $0.038 \mathrm{~mm}$. A proportion of sample was defatted by blending with hexane $(1: 5, \mathrm{w} / \mathrm{v}, 2$ min two times) at the ambient temperature for the extraction of phenolic compounds. All samples were packed in polythene pouches and stored at $-80^{\circ} \mathrm{C}$ until used within one week for extraction of phenolic compounds and in vitro digestion. 


\subsection{Extraction of soluble phenolic compounds of finger millet foods}

Soluble phenolic compounds were extracted using 70\% (v/v) aqueous acetone. In brief, defatted meal $(5 \mathrm{~g})$ was mixed with 100 $\mathrm{mL}$ of $70 \%$ aqueous acetone in a capped conical flask and placed in a shaking water bath (BT 680D, YIH DER Co., Ltd, New Taipei city, Taiwan) at $50{ }^{\circ} \mathrm{C}$, stirring at a speed of $175 \mathrm{rpm}$ for $40 \mathrm{~min}$. The resulting slurry was centrifuged for $5 \mathrm{~min}$ at 3,000 g (Refrigerated centrifuge 3-18R TOMOS Life Science Group, NJ, USA) and the supernatant was collected. The extraction was repeated for twice. Combined supernatants were evaporated in a rotary evaporator (IKA RV-10, IKA®-Werke GmbH \& Co. KG, Staufen, Germany) at $40{ }^{\circ} \mathrm{C}$. During all stages, extracts were protected from light by covering the containers with aluminium foil. Concentrated samples were freeze dried at $-55^{\circ} \mathrm{C}$, and 0.012 mbar. Lyophilized extracts were stored at $-80{ }^{\circ} \mathrm{C}$ for further analysis. The residues of all samples were stored at $-80{ }^{\circ} \mathrm{C}$ for the extraction of bound phenolics.

\subsection{Extraction of bound phenolic compounds of finger millet foods}

Bound phenolic compounds were extracted according to the method described by Chandrasekara and Shahidi (2010). The residues obtained after extraction of soluble phenolic compounds were hydrolyzed with $2 \mathrm{M} \mathrm{NaOH}$ at room temperature for $4 \mathrm{~h}$ in a shaking water bath bath under a nitrogen blanket. The $\mathrm{pH}$ of the resulting slurry was adjusted to 2 with $6 \mathrm{M} \mathrm{HCl}$. The bound phenolic compounds were extracted three times with diethyl ether and ethyl acetate $(1: 1, \mathrm{v} / \mathrm{v})$ and desolventized at $30^{\circ} \mathrm{C}$ using a rotary evaporator. Phenolic compounds were reconstituted to a known volume of methanol and stored at $-80^{\circ} \mathrm{C}$ until used for further analysis.

\subsection{HPLC analysis}

Ferulic acid content of soluble and bound phenolic extracts of finger millet food preparations was determined using HPLC analysis. The reverse phase HPLC analysis was conducted by using a Shimadzu HPLC system (Shimadzu, SPD 20 A, Shimadzu Corporation, Kyoto, Japan) and an II ${ }^{\mathrm{TM}}$ Pinnacle C-18 column $150 \times 4.6$ ) $\mathrm{mm}, 5 \mu \mathrm{m}, 110 \mathrm{~A} 0$, Restsk International (Bellefonte, PA, USA). The mobile phase consisted of methanol/water $(30: 70, \mathrm{v} / \mathrm{v})$ and the flow rate was adjusted to $0.4 \mathrm{~mL} / \mathrm{min}$. The ferulic acid was detected at $280 \mathrm{~nm}$. All samples were filtered through a $0.45 \mu \mathrm{m}$ PTFE membrane syringe filter (Whatman Inc., Florham Park, NJ, USA) before injection. The external standard method in which ferulic acid was chromatographed under similar conditions was used to identify and quantify the ferulic acid in food samples. The results were expressed as $\mu \mathrm{g} / \mathrm{g}$ dry matter $(\mathrm{dm})$ of finger millet food.

\subsection{Simulated in vitro gastric digestion}

In vitro gastric digestion of food samples was performed following previously reported methods (Marambe et al., 2011; Chandrasekara and Shahidi, 2012). In brief, $10.0 \mathrm{~g}$ of freeze dried, ground food sample was weighed $(1.0 \mathrm{~g})$ and placed in a screw capped $(50 \mathrm{~mL})$ centrifuged tube. Each sample was added with distilled water (15 $\mathrm{mL}$ ) and $10 \mathrm{~mL}$ of $0.85 \%(\mathrm{w} / \mathrm{v})$ sodium chloride solution followed by incubation at $37^{\circ} \mathrm{C}$ for 10 min using a shaking water bath at
$120 \mathrm{rpm}$. Glass marbles were added to each tube for uniform mixing during incubation. After reaching $37^{\circ} \mathrm{C}, 1 \mathrm{~mL}$ of $\alpha$-amylase ( 50 units $/ \mathrm{mL}$ ) diluted in $20 \mathrm{mM}$ sodium phosphate buffer ( $\mathrm{pH}$ 6.9) containing $1 \mathrm{mM}$ calcium chloride was added to each sample. At the end of $5 \mathrm{~min}, 4.5 \mathrm{~mL}$ of $0.15 \mathrm{M} \mathrm{HCl}$ were added and the $\mathrm{pH}$ was maintained below 2.5. One millilitre of porcine pepsin $(20$ $\mathrm{mg} / \mathrm{mL}$ ) dissolved in $20 \mathrm{mM} \mathrm{HCl}$ was mixed with each sample and incubated at $37^{\circ} \mathrm{C}$ for $2 \mathrm{~h}$ under the same conditions. The gastric digestion was terminated by raising the $\mathrm{pH}$ of the digest to 6.9 by adding $1 \mathrm{M} \mathrm{NaOH}$.

\subsection{Simulated in vitro static intestinal digestion}

The static intestinal digestion model (SIDM) was used as previously reported by Chandrasekara and Shahidi (2012). In this, total gastric digest of food samples obtained from the gastric phase of digestion was added with $4 \mathrm{~mL}$ of bile salt $(150 \mathrm{mg} / \mathrm{mL})$ in 0.15 $\mathrm{M}$ sodium bicarbonate solution, and $4 \mathrm{~mL}$ of porcine pancreatin $(18.75 \mathrm{mg} / \mathrm{mL})$ in $0.15 \mathrm{M}$ sodium bicarbonate solution in a conical flask and mixed. The digestion was continued for another $3 \mathrm{~h}$. Gastrointestinal digest was centrifuged at $4,000 \mathrm{~g}$ for $10 \mathrm{~min}$ to separate the residues of undigested food samples. The centrifugation was repeated twice after adding $20 \mathrm{~mL}$ of distilled water each time to collect the leftover soluble compounds from the slurry and supernatants were combined. Lyophilized supernatant was used to determine the bioaccessible content of phenolics and their antioxidant activities of the intestinal digestion.

\subsection{Simulated in vitro dynamic intestinal digestion}

The dynamic intestinal digestion model (DIDM) applied in the present study was a simplified version reported in a previous study by Marambe et al. (2011). In this model, a tube made of dialysis membrane (Visking dialysis tubing, flat width- $29 \mathrm{~mm}$, OD * 44 $\mathrm{mm}$, molecular weight cut off $1 \mathrm{kDa}$ ) was used as the simulated small intestinal compartment. The gastric digest ( $\mathrm{pH}$ 6.9) obtained from the previous step was transferred to the dialysis tube. Subsequently, bile salt and porcine pancreatin were added into the dialysis tube containing gastric digest and was mixed. The dialysis tube was then immersed in a conical flask containing $300 \mathrm{~mL}$ of buffer solution containing $20 \mathrm{mM}$ sodium phosphate and $1 \mathrm{mM}$ calcium chloride ( $\mathrm{pH}$ 6.9). Digestion was continued for $3 \mathrm{~h}$ using the shaking water bath at $120 \mathrm{rpm}$ under the same temperature as for gastric digestion. Buffer solution in the conical flask was replaced at the end of every hour for a $3 \mathrm{~h}$ period and was pooled at the end of intestinal digestion phase. The pooled buffer solution with permeable digestion products (dialysate) and retained solution in the dialysis tube (retentate) were collected. Retentate was centrifuged at 4,000 g for $10 \mathrm{~min}$ to separate the undigested residues. The centrifugation was repeated twice after adding $20 \mathrm{~mL}$ of distilled water each time to collect the leftover soluble compounds from the retentate. Indigestible residues were used for the in vitro colonic fermentation. All samples were stored at $-80{ }^{\circ} \mathrm{C}$ until used for further analysis.

Enzyme blanks prepared under similar conditions were used for the correction of interferences from the digestive enzymes and buffers for both gastric and intestinal phases. Three replicates were used for each food sample and blanks employed. Potential bioavailability $(\%)$ was calculated as follows: Bioavailability $(\%)=100 * \mathrm{Y} / \mathrm{Z}$ where $\mathrm{Y}$ is phenolic content or antioxidant activity of the lyophilized dialysate obtained by DIDM and Z is phenolic content or antioxidant activity of the lyophilized supernatant obtained by SIDM. 


\subsection{Aqueous extraction of phenolics of finger millet foods}

To compare the effect of gastrointestinal $\mathrm{pH}$ and enzymes during the digestion process, finger millet foods were incubated only with distilled water under similar conditions to represent the time period of both gastric phase and intestinal phase of digestion.

\subsection{In vitro colonic fermentation}

The microbial fermentation was carried out using lyophilized residue obtained after in vitro digestion (Chandrasekara and Shahidi, 2012).

\subsection{Culture medium}

The culture medium was prepared as explained by Chandrasekara and Shahidi (2012). The culture medium was boiled for $15 \mathrm{~min}$ for sterilization and cooled to room temperature. The $\mathrm{pH}$ of culture medium was adjusted to 7 with $5 \mathrm{M} \mathrm{HCl}$. Filter sterilized Lcysteine was added at $250 \mathrm{mg} / \mathrm{L}$ as a reducing agent to culture medium and stored at $4{ }^{\circ} \mathrm{C}$ until used. A separate control culture medium with added methylene blue as a redox indicator was maintained to ensure the reducing environment in the medium.

\subsection{Preparation of inoculum}

Fresh faeces were collected from a male pig from the Animal Handling Unit of the Department of Livestock, and Avian Sciences, Wayamba University of Sri Lanka. The age and weight of the animal were 5 years and $90-100 \mathrm{~kg}$, respectively. The animal had not received antibiotics at any time. Fresh faeces were immediately collected in a closed jar under anaerobic environment and were quickly homogenized with sterilized culture medium using a mortar and pestle. The prepared $10 \%(\mathrm{w} / \mathrm{v})$ faecal slurry was filtered using gauze to remove large particles and used as the inoculum for the fermentation.

\subsection{In vitro colonic fermentation}

The microbial fermentation was carried out using the lyophilized residue obtained after in vitro digestion as explained by Chandrasekara and Shahidi (2012). Sterile culture medium (5 mL) was added to the food residue in a sterilized $50 \mathrm{~mL}$ centrifuge tube and kept at $4{ }^{\circ} \mathrm{C}$ for $16 \mathrm{~h}$ to ensure adequate hydration. The inoculation was carried out while flasks were kept at room temperature. Immediately after the addition of inoculum $(20 \mathrm{~mL})$, the flasks were sealed and incubated at $37{ }^{\circ} \mathrm{C}$ for $24 \mathrm{~h}$ in a shaking water bath at $100 \mathrm{rpm}$. Anaerobic conditions were maintained during the fermentation procedure. A separate blank devoid of any sample was incubated under similar conditions. At the end of incubation, fermented slurries were centrifuged for $15 \mathrm{~min}$ at $4,000 \mathrm{~g}\left(4^{\circ} \mathrm{C}\right)$ and the collected supernatants were immediately stored at $-80^{\circ} \mathrm{C}$ and lyophilized at $-55^{\circ} \mathrm{C}$, and $0.012 \mathrm{mbar}$.

\subsection{Total phenolic content (TPC)}

The TPC of phenolic extracts was determined as previously explained (Chandrasekara and Shahidi, 2010). The absorbance of the resulting blue colour supernatant was measured at $725 \mathrm{~nm}$ (UV-
VIS Spectrophotometer, LabomedInc, Los Angeles, CA, USA) with appropriate blanks for background subtractions. The TPC was determined using a standard curve prepared with ferulic acid and expressed as $\mu \mathrm{mol}$ ferulic acid equivalents (FAE)/g dry matter $(\mathrm{dm})$ of food sample.

\subsection{Total flavonoid content (TFC)}

The TFC was determined by a spectrophotometric method (Chandrasekara and Shahidi, 2010). The absorbance of reaction mixture was read at $510 \mathrm{~nm}$ against an appropriate blank. The TFC was calculated from a standard curve for catechin and values were expressed as $\mu \mathrm{mol}$ catechin equivalents $(\mathrm{CE}) / \mathrm{g}$ of food $(\mathrm{dm})$.

\subsection{Trolox equivalent antioxidant capacity (TEAC)}

The TEAV was determined as previously explained (Chandrasekara and Shahidi, 2010). The absorbance value of the reaction mixture was read at $734 \mathrm{~nm}$ immediately at the point of mixing $\left(\mathrm{t}_{0}\right)$ and after $6 \mathrm{~min}\left(\mathrm{t}_{6}\right)$. The decrease in absorbance at $734 \mathrm{~nm}$ after $6 \mathrm{~min}$ of addition of trolox and extract was calculated using the equation: $\Delta \mathrm{A}$ trolox $=\left(\mathrm{At}_{0}\right.$, trolox $-\mathrm{At}_{6}$, trolox $)-\left(\mathrm{At}_{0}\right.$, blank $-\mathrm{At} 6$, blank $)$, where $\Delta \mathrm{A}$ is the reduction of absorbance and $\mathrm{A}$ the absorbance at a given time. TEAC values were expressed as $\mu \mathrm{mol}$ trolox equivalents $(\mathrm{TE}) / \mathrm{g}$ of food $(\mathrm{dm})$.

\subsection{DPPH radical scavenging activity (DRSA)}

The DRSA was determined by a spectrophotometric method (Lee ei al., 2007). Briefly, the sample $(0.04 \mathrm{~mL} ; 1 \mathrm{mg} / \mathrm{mL})$ in methanol was added to $1.96 \mathrm{~mL}$ of methanolic solution of DPPH (60 $\mu \mathrm{M})$. The solutions were vortexed and allowed to stand at room temperature in the dark for $20 \mathrm{~min}$. The absorbance of the solutions was measured at $517 \mathrm{~nm}$ and appropriate blanks were used for background subtraction. The results were expressed as $\mu \mathrm{mol}$ $\mathrm{TE} / \mathrm{g}$ of food (dm).

\subsection{Reducing power (RP)}

The RP of samples was determined using a spectrophotometric method (Chandrasekara and Shahidi, 2010). The absorbance values were read at $700 \mathrm{~nm}$. The standard curve was prepared using ascorbic acid. The results were expressed as $\mu \mathrm{mol}$ ascorbic acid equivalents (AAE)/g of food (dm).

\subsection{Ferrous ion chelating activity (FICA)}

The analysis was performed as previously explained (Chandrasekara and Shahidi, 2010). Different concentrations (0.05-2 mM) of EDTA were used to prepare the standard curve. The percent inhibition of ferrozine-ferrous ion complex formation was calculated by the following equation: metal chelating effect $(\%)=[1$-(absorbance of the sample - absorbance of the control) $] 100$. The results were expressed as $\mu \mathrm{mol}$ EDTA equivalents/g of food (dm).

\subsection{Statistical analysis}

All experiments were carried out in triplicates and data were re- 
Table 1. Phenolic content and antioxidant activities (per g of dry matter) of soluble and insoluble-bound phenolic extracts of finger millet foods

\begin{tabular}{|c|c|c|c|c|c|c|c|}
\hline & $\begin{array}{l}\text { TPC* } \mu \text { mol feru- } \\
\text { lic acid equiv }\end{array}$ & $\begin{array}{l}\text { TFC* } \mu \text { mol } \\
\text { catechin equiv }\end{array}$ & $\begin{array}{l}\text { TEAC* } \mu \mathrm{mol} \\
\text { trolox equiv }\end{array}$ & $\begin{array}{l}\text { DRSA* } \mu \text { mol } \\
\text { trolox equiv }\end{array}$ & $\begin{array}{l}\text { RP* } \mu \text { mol ascorbic } \\
\text { acid equiv }\end{array}$ & $\begin{array}{l}\text { FICA* } \mu \text { mol } \\
\text { EDTA equiv }\end{array}$ & Ferulic acid $\mu \mathrm{g}$ \\
\hline \multicolumn{8}{|c|}{ Soluble phenolic extract } \\
\hline Raw flour & $32.5 \pm 0.4^{a}$ & $11.0 \pm 1.3^{\mathrm{a}}$ & $1.7 \pm 0.1^{\mathrm{a}}$ & $21.0 \pm 0.8^{a}$ & $12.4 \pm 0.2^{\mathrm{a}}$ & $8.8 \pm 0.0^{a}$ & $101.8 \pm 1.7^{a}$ \\
\hline Rotti & $31.3 \pm 2.3^{\mathrm{ab}}$ & $8.4 \pm 0.9^{b}$ & $0.9 \pm 0.3^{b}$ & $10.3 \pm 1.2^{b}$ & $27.4 \pm 0.4^{b}$ & $41.1 \pm 0.4^{b}$ & $213.3 \pm 17.2^{b}$ \\
\hline Pittu & $29.6 \pm 0.6^{b}$ & $9.6 \pm 0.5^{b}$ & $1.2 \pm 0.1^{\mathrm{b}}$ & $8.0 \pm 0.3^{c}$ & $20.4 \pm 0.7^{c}$ & $40.5 \pm 1.5^{b}$ & $116.9 \pm 3.8^{c}$ \\
\hline Halape & $43.5 \pm 1.4^{c}$ & $8.1 \pm 0.8^{b}$ & $1.3 \pm 0.4^{c}$ & $12.6 \pm 1.8^{d}$ & $31.9 \pm 0.7^{d}$ & $99.2 \pm 0.8^{c}$ & $342.8 \pm 37.1^{d}$ \\
\hline Thalapa & $54.4 \pm 1.5^{d}$ & $17.2 \pm 1.3^{c}$ & $5.2 \pm 0.4^{d}$ & $15.4 \pm 1.7^{e}$ & $32.7 \pm 1.0^{d}$ & $91.6 \pm 2.5^{d}$ & $125.1 \pm 41.0^{\mathrm{e}}$ \\
\hline Porridge & $79.6 \pm 1.6^{e}$ & $29.6 \pm 0.2^{d}$ & $5.1 \pm 0.3^{d}$ & $50.8 \pm 0.6^{f}$ & $55.6 \pm 0.5^{e}$ & $170.8 \pm 1.5^{\mathrm{e}}$ & $556.4 \pm 14.2^{f}$ \\
\hline \multicolumn{8}{|c|}{ Bound phenolic extract } \\
\hline Raw flour & $2.2 \pm 0.1^{\mathrm{a}}$ & $0.1 \pm 0.02^{\mathrm{a}}$ & $0.70 \pm 0.03^{a}$ & $0.36 \pm 0.04^{\mathrm{a}}$ & $3.37 \pm 0.7^{a}$ & $1.42 \pm 0.01^{a}$ & $472.5 \pm 0.6^{a}$ \\
\hline Rotti & $4.0 \pm 0.3^{b}$ & $0.8 \pm 0.01^{b}$ & $0.12 \pm 0.01^{b}$ & $1.6 \pm 0.2^{b}$ & $10.8 \pm 1.0^{b}$ & $2.4 \pm 0.02^{b}$ & $0.04 \pm 0.01^{b}$ \\
\hline Pittu & $4.2 \pm 0.3^{b}$ & $0.9 \pm 0.01^{c}$ & $0.12 \pm 0.01^{b}$ & $1.0 \pm 0.2^{c}$ & $9.5 \pm 1.4^{b}$ & $2.8 \pm 0.02^{b}$ & $0.02 \pm 0.001^{c}$ \\
\hline Halape & $6.2 \pm 0.3^{c}$ & $1.4 \pm 0.06^{d}$ & $0.17 \pm 0.03^{c}$ & $2.3 \pm 0.3^{d}$ & $16.8 \pm 0.6^{c}$ & $3.9 \pm 0.02^{c}$ & $0.03 \pm 0.001^{b c}$ \\
\hline Thalapa & $7.2 \pm 0.4^{d}$ & $2.5 \pm 0.01^{\mathrm{e}}$ & $0.24 \pm 0.03^{d}$ & $2.8 \pm 0.8^{d}$ & $24.1 \pm 2.6^{d}$ & $7.2 \pm 0.2^{d}$ & $0.02 \pm 0.01^{c}$ \\
\hline Porridge & $11.8 \pm 0.3^{e}$ & $2.8 \pm 0.01^{f}$ & $0.38 \pm 0.03^{e}$ & $2.1 \pm 0.1^{d}$ & $32.5 \pm 0.1^{\mathrm{e}}$ & $8.5 \pm 0.07^{d}$ & $0.05 \pm 0.01^{b}$ \\
\hline
\end{tabular}

*Abbreviations: TPC, Total phenolic content; TFC, Total flavanoid content; TEAC, Trolox equivalent antioxidant capacity; DRSA, 2,2-diphenyl-1-picrylhydrazyl (DPPH) radical scavenging ability; RP, Reducing power; FICA, Ferous ion chelating ability; EDTA, Ethylenediaminetetraacetic acid: dm, dry matter. The same letters in each column seperately for soluble and insoluble-bound phenolic extracts are not significantly different $(>0.05)$.

ported as mean \pm standard deviation. The differences of mean values among different finger millet foods were determined by one way analysis of variance (ANOVA) followed by Tukeys Honestly Significant Difference (HSD) multiple rank tests at $p \leq 0.05$, significance level. All statistical analyses were performed by SPSS version 16.

\section{Results and discussion}

To the best of our knowledge this study reports for the first time the bioaccessibility and potential absorption of phenolics of finger millet foods released under simulated physiological conditions using dynamic in vitro digestion and microbial fermentation models. The phenolic contents of foods free of coconut were 33, 26, 46, 59 and $81 \mu \mathrm{mol}$ ferulic acid equivalents per gram of dry matter (FAE/g dm), of Rotti, Pittu, Halapa and Thalapa, and porridge, respectively. Addition of scraped coconut or coconut milk did not bring any significant difference in TPC in the foods so prepared (Table 1).

\subsection{TPC of finger millet foods}

The TPC of soluble and bound phenolic extracts ranged from 29.6 to 79.6 and from 2.2 to $11.8 \mu \mathrm{mol} \mathrm{FAE} / \mathrm{g}$ (dm), respectively (Table 1). The TPC varied depending on the hydrothermal treatment used in each food preparation and TPC of extracts was in the order of porridge $>$ Thalapa $>$ Halape $>$ Pittu $>$ Rotti. Pressure cooking and open boiling increased TPC of soluble phenolic extracts of foods by 33 and $>67 \%$, respectively compared to their raw counterparts (Table 1). A previous study showed that TPC of native finger millet flour was reduced by $50 \%$ after sprouting or pressure cooking (Hithamini and Sirinivasan, 2014). Furthermore, 12-19\% reduction was observed after open boiling of finger millet flour.
However, roasting of finger millet grains increased the TPC by 17\% (Hithamini and Sirinivasan, 2014). A previous study (Chandrasekara et al., 2012) demonstrated that open boiling of finger millet dehulled grains with water for 15 min reduced the TPC by 11 to $36 \%$. Further, steaming and microwave cooking increased the phenolic contents of foxtail and proso millet, though decreased in barnyard millet (Pradeep and Yadahally, 2015). In addition, roasting reduced the phenolic contents in pearl millet (Fasai and Ilayo, 2009) whereas boiling and roasting increased the TPC of barley (Infante et al., 2010). The changes in phenolic content of cereals depend on the type of grain, the preparation method or the cooking procedure employed (Shahidi and Chandrasekara, 2014). Further process induced phenolic content and antioxidant potential changes in soluble and bound phenolic contents have been reported for lentils (Yeo and Shahidi, 2015). The present findings evidence that variety of millet, time of hydrothermal treatment applied and nature of matrix may affect the TPC of finger millet based foods.

In the present study, TPC of bound phenolic extracts of raw flour and finger millet foods were lower compared to those of soluble extracts. This is in agreement with the results of earlier studies (Chandrasekara and Shahidi, 2010, 2011). The TPC of bound phenolic extracts of finger millet foods was significantly higher than that of raw flour (Table 1). This could be due to the release of bound phenolic compounds upon hydrothermal treatment during cooking of finger millet foods.

\subsection{TFC of finger millet foods}

The TFC of soluble phenolic extracts of raw flour was $11.0 \mu \mathrm{mol}$ catechin equivalents $(\mathrm{CE}) / \mathrm{g} \mathrm{dm}$ and the contents reduced during pressure cooking, dry roasting and steaming by 26,23 and $13 \%$, respectively (Table 1). Foods prepared using open boiling showed a higher TFC of soluble phenolic extracts by 0.5 and 1.5 folds for Thalapa and porridge, respectively, compared to that of raw flour. 
Table 2. Bioaccessible content ( $\mu \mathrm{mol} / \mathrm{g}$ of $\mathrm{dm})$, absorbable (\%) of finger millet food phenolics subjected to in vitro digestion and colonic fermentation

\begin{tabular}{|c|c|c|c|c|c|c|c|c|}
\hline & \multicolumn{2}{|c|}{ Aqueous extraction } & \multicolumn{2}{|c|}{$\begin{array}{l}\text { Static intestinal digestion } \\
\text { bioaccessibility }\end{array}$} & \multicolumn{3}{|c|}{ Dynamic intestinal digestion } & \multirow{2}{*}{$\begin{array}{l}\text { Colonic } \\
\text { fermentation }\end{array}$} \\
\hline & $\begin{array}{l}\text { Gastric } \\
\text { phase }\end{array}$ & $\begin{array}{l}\text { Gastric + } \\
\text { Intestinal }\end{array}$ & Gastric & $\begin{array}{l}\text { Gastric + } \\
\text { Intestinal }\end{array}$ & Retentate* & Dialysate** & $\begin{array}{l}\text { Absorb- } \\
\text { able (\%) }\end{array}$ & \\
\hline \multicolumn{9}{|c|}{ Total phenolic content (TPC) $\mu \mathrm{mol}$ ferulic acid equiv/g of dm } \\
\hline Rotti & $15.3 \pm 1.3^{\mathrm{a}}$ & $22.1 \pm 0.9^{a}$ & $39.6 \pm 4.0^{\mathrm{a}}$ & $41.5 \pm 3.6^{\mathrm{a}}$ & $23.2 \pm 0.9^{\mathrm{a}}$ & $24.6 \pm 1.0^{\mathrm{a}}$ & 59.3 & $22.1 \pm 3.0^{\mathrm{a}}$ \\
\hline Pittu & $13.0 \pm 1.0^{\mathrm{a}}$ & $18.7 \pm 0.5^{\mathrm{a}}$ & $30.6 \pm 1.2^{\mathrm{b}}$ & $70.1 \pm 1.6^{\mathrm{b}}$ & $27.6 \pm 0.6^{b}$ & $40.2 \pm 2.8^{b}$ & 57.3 & $26.8 \pm 1.7^{b}$ \\
\hline Halape & $10.6 \pm 1.6^{b}$ & $24.4 \pm 4.1^{\mathrm{b}}$ & $21.5 \pm 2.6^{c}$ & $68.1 \pm 1.2^{b}$ & $45.0 \pm 0.1^{c}$ & $14.2 \pm 1.0^{c}$ & 20.9 & $24.3 \pm 4.1^{c}$ \\
\hline Thalapa & $18.7 \pm 1.4^{\mathrm{c}}$ & $25.7 \pm 2.2^{\mathrm{b}}$ & $23.2 \pm 2.5^{c}$ & $41.5 \pm 1.5^{\mathrm{a}}$ & $19.7 \pm 1.3^{\mathrm{a}}$ & $20.4 \pm 2.4^{d}$ & 49.2 & $15.8 \pm 2.6^{d}$ \\
\hline Porridge & $27.6 \pm 1.0^{d}$ & $44.7 \pm 1.4^{c}$ & $27.5 \pm 2.9^{b}$ & $69.2 \pm 4.9^{b}$ & $27.9 \pm 2.3^{b}$ & $39.4 \pm 0.1^{b}$ & 57.0 & $20.0 \pm 2.4^{\mathrm{a}}$ \\
\hline \multicolumn{9}{|c|}{ Total flavonoid content (TFC) $\mu \mathrm{mol}$ catechin equiv/g of $\mathrm{dm}$} \\
\hline Rotti & $4.5 \pm 0.9^{a}$ & $8.7 \pm 0.2^{\mathrm{a}}$ & $11.7 \pm 0.8^{\mathrm{a}}$ & $13.4 \pm 0.7^{\mathrm{a}}$ & $8.6 \pm 0.7^{a}$ & $3.4 \pm 0.5^{\mathrm{a}}$ & 25.3 & $4.50 \pm 0.1^{\mathrm{a}}$ \\
\hline Pittu & $8.8 \pm 0.3^{b}$ & $9.7 \pm 0.2^{b}$ & $9.9 \pm 1.5^{b}$ & $27.9 \pm 0.4^{b}$ & $19.3 \pm 0.1^{b}$ & $9.1 \pm 0.5^{b}$ & 32.6 & $3.30 \pm 0.2^{b}$ \\
\hline Halape & $6.9 \pm 0.3^{c}$ & $19.2 \pm 0.8^{c}$ & $8.3 \pm 1.7^{c}$ & $23.5 \pm 1.2^{c}$ & $14.7 \pm 0.7^{c}$ & $8.5 \pm 0.2^{b}$ & 36.2 & $2.01 \pm 0.5^{c}$ \\
\hline Thalapa & $8.8 \pm 0.1^{b}$ & $11.0 \pm 0.2^{d}$ & $9.3 \pm 0.3^{b}$ & $23.4 \pm 0.3^{c}$ & $7.1 \pm 0.4^{d}$ & $14.2 \pm 0.1^{c}$ & 60.7 & $3.69 \pm 0.1^{d}$ \\
\hline Porridge & $10.5 \pm 1.0^{d}$ & $12.7 \pm 0.5^{e}$ & $15.2 \pm 0.3^{d}$ & $18.5 \pm 0.7^{d}$ & $7.1 \pm 1.2^{d}$ & $11.0 \pm 0.2^{d}$ & 59.5 & $5.64 \pm 0.1^{\mathrm{e}}$ \\
\hline
\end{tabular}

*Retentate, non-dialized fraction after intestinal digestion and represent unabsorbed compounds; **Dialysate, dialyzed fraction after intestinal digesation and represent absorbed compounds; dm, dry matter, The same letters in each column are not significantly different $(>0.05)$

All four food preparation methods showed higher TFC of bound phenolic extracts compared to that of the raw flour. In general, the highest TFC was reported for bound phenolic extracts of the porridge while the lowest was found for that of Rotti. Earlier it was reported (Hithamini and Sirinivasan, 2014) that pressure cooking for 15-20 min and open pan boiling for 15 min reduced the TFC of finger millet flour by 68 and $10 \%$, respectively. Heat treatments was reported to increase the flavonoid content of pearl millet grains (Pushparaj and Urooj, 2014). However, roasting of barley at $327^{\circ} \mathrm{C}$ resulted in a significant decrease of the catechin content (Duh et al., 2001). The changes of phenolic contents of processed millets could be due to the release of insoluble bound phenolic compounds from the food matrix, condensation/polymerisation and oxidation of phenolics, thermal degradation, as well as depolymerisation of high molecular weight phenolics such as condensed tannins and formation of Maillard reaction products (Shahidi and Chandrasekara, 2014; Doudu 2014; Pradeep and Yadahally, 2015).

\subsection{Ferulic acid content of foods}

In the present study, HPLC analysis showed that the ferulic acid content of soluble and bound phenolic contents of raw flour were 101.8 and $427.45 \mu \mathrm{g} / \mathrm{g}(\mathrm{dm})$, respectively. Ferulic acid content of bound phenolics was 4.6 times higher than that of the soluble fraction (Table 1). Thermal processing increased the ferulic acid content in the soluble extracts of the foods tested, namely Rotti, Pittu, Halape, Thalapa and porridge by 106, 115, 237, 23, and 447\%, respectively. In agreement, another study showed that thermal processing at $115{ }^{\circ} \mathrm{C}$ for 10,25 and $50 \mathrm{~min}$ increased the free ferulic acid content of sweet corn by $239.9,553.3$ and $896.3 \%$, respectively (Dewanto et al., 2002). Furthermore, thermal processing for $25 \mathrm{~min}$ at 100,115 , and $121{ }^{\circ} \mathrm{C}$ increased ferulic acid content by $124.8,553.3$ and $886.6 \%$, respectively (Dewanto et al., 2002). This could be due to the release of ferulic acid from its bound form during the application of heat. In the present study, ferulic acid con- tent of bound phenolics of food samples were significantly lower compared to that of the raw flour (Table 2). All four food preparation methods used in the present work decreased the ferulic acid content in the bound phenolic extracts by approximately $99 \%$. In agreement, several previous studies showed increased ferulic acid content in the soluble phenolic extracts and decreased content in the bound extracts of cooked cereals compared to their raw counterparts (Dewanto et al., 2002; Ragaee et al., 2014). Foregoing evidences suggest that the change their food matrix undergoes during food preparation could release bound ferulic acids in cell wall matrix. The content may vary depending on time and severity of the hydrothermal treatment. This further emphasizes the importance of the determination of bioactive compounds and their activities by prepared foods compared with their native counterparts. However, Yeo and Shahidi (2015) reported that the increase in the content of soluble phenolics was less than that released from the insolublebound fraction in lentils and lentil by-products. This change could be due to interactions of phenolics with proteins present (Yeo and Shahidi, 2015).

\subsection{Antioxidant activities of finger millet foods}

Antioxidant activities, as measured by TEAC, DRSA, RP and FICA of soluble and insoluble bound phenolic extracts of finger millet foods are presented in Table 1. The TEAC of soluble and bound phenolic extracts ranged from 0.9 to 5.2 and 0.7 to 0.38 $\mu \mathrm{mol}$ of TE/g $(\mathrm{dm})$, respectively. The TEAC of soluble phenolic extract of raw flour was $1.7 \mu \mathrm{mol}$ of $\mathrm{TE} / \mathrm{g}(\mathrm{dm})$, which was reduced upon pressure cooking, dry roasting and steaming by 24 , 47 and $29 \%$, respectively. The TEAC of soluble phenolic extract of Thalapa and porridge prepared by open boiling were 3 times higher than that of raw flour. Furthermore, all four cooking methods decreased the TEAC of the insoluble-bound phenolic extracts.

Porridge made of finger millet showed the highest DRSA of the soluble phenolic extracts (Table 1). Rotti, Pittu, Halape and 
Thalapa had 2, 2.6. 1.6, and 1.4 times lower DRSA, respectively compared to that of soluble phenolic extracts of raw flour. In addition, all four food preparation methods increased the DRSA of insoluble bound phenolic extracts of finger millet foods compared to that of raw flour. A previous study (Chandrasekara and Shahidi, 2012) reported that boiling reduced the DRSA of soluble phenolic extracts of finger millet varieties $11-36 \%$ compared to that of raw grains. This could be due to different analytical methods used in the two studies. However, boiling, roasting and pressure cooking significantly increased the antioxidant activity of pearl millet (Pushparaj and Urooj, 2014) in agreement with the present work. Another study (Pradeep and Yadahally, 2015) also showed increased radical scavenging activity of little millet by roasting $(95.5 \%)$ and steaming $(93.4 \%)$.

The RP of soluble and insoluble bound phenolic extracts of foods revealed that the food preparation methods have an effect on the antioxidant activities as measured by reducing power of phenolics of finger millets (Table 1). Preparation of Rotti, Halape, Pittu, Thalapa and porridge from finger millet flour increased the RP of soluble and insoluble bound phenolic extracts compared to the raw finger millet flour.

The FICA of soluble and insoluble bound phenolic extracts of finger millet foods ranged from 40.5 to 170.8 and 2.4 to $8.5 \mu \mathrm{mol}$ of ethylenediaminetetraacetic acid (EDTA) equivalents/g (dm), respectively. All four food preparation methods increased the FICA of soluble and insoluble bound phenolic extracts of foods compared to those of the raw flour. The results further emphasize the importance of selecting a method for the determination of antioxidant activity of prepared foods.

\subsection{Bioaccessibility and absorption of phenolics of finger millet foods}

The TPC of foods after enzymatic digestion of gastric phase and intestinal phase ranged from 21.5 to 39.6 and 41.5 to $69.2 \mu \mathrm{mol}$ of FAE $/ \mathrm{g}(\mathrm{dm})$, respectively (Table 2$)$. In a previous study, it was shown that there was no significant difference between TPC of aqueous extracts and extracts obtained after stimulated gastrointestinal $\mathrm{pH}$ conditions ( $\mathrm{pH}$ treated) (Chandrasekara and Shahidi, 2012). Therefore, in the present study aqueous extractions without $\mathrm{pH}$ treatments under the same experimental conditions were used to compare the extractions rendered in the digestion process. In general, the TPC of all finger millet foods increased stepwise from gastric to intestinal digestion. At the end of gastric phase 2.5 times more phenolics were released than those of corresponding aqueous extracts of finger millet foods. As shown in a previous work (Chandrasekara and Shahidi, 2012) 2 to 5 times more TPC were released from boiled millet samples of kodo, finger, pearl, foxtail, and proso at the end of gastric phase digestion. Another study showed that in vitro digested pearl millet had a higher TPC than that of aqueous methanolic extracts (Minaxi et al., 2013). Gastric digestion of proteins may also release the phenolic compounds bound to proteins (Konishi et al., 2006).

In this study, 1.5 to 4 times more total phenolics were released at the end of intestinal phase compared to those of corresponding aqueous extracts of finger millet foods (Table 2). Phenolic compounds released after gastric and intestinal phases of digestion may have the ability to exert a localized antioxidant effect in the gastrointestinal tract. The potential absorption of total phenolics of finger millet foods ranged from 21 to $59 \%$ (Table 2). The absorption of phenolics in foods was in the order of Rotti $>$ Pittu $>$ Porridge $>$ Thalapa $>$ Halape. However, it should be noted that IDDM used in the present study represented only the paracellular absorption of the digestive compounds. In the human digestive tract both transcellular and paracellular routes are used for the absorption of digested components in foods.

The impact of gastrointestinal digestion on TFC of finger millet foods are shown in Table 3. The pattern of release was similar to TPC with stepwise release from the gastric phase to the intestinal phase. After the gastric phase digestion the highest TFC was found in the porridge while Pittu had the highest TFC after the intestinal phase digestion. This evidence shows the difference in the way of releasing flavonoids of different foods within the digestive system. The interaction of flavonoids with proteins present in enriched wheat breads has an impact on the antioxidant capacity and bioaccessibility of flavonoids (Swieca et al., 2013). Therefore, the proteins or other compounds present in individual foods might change the bioaccessibility of flavonoids in different finger millet foods.

In this work, Thalapa had 2.3 times higher absorption of flavonoids than that of Rotti which showed the lowest (Table 2). Furthermore, the flavonoids remained unabsorbed (30 to 70\%) in the intestinal phase and may exert local antioxidant effect within the small intestine. Flavonoid compounds are substrates for several enzymes located in the small intestine and colon, and hepatic metabolism (Swieca et al., 2013).

\subsection{Antioxidant activities of bioaccessible and absorbable phe- nolics of finger millet foods}

Table 3 presents the antioxidant activities as determined by TEAC, DRSA, RP and FICA in in vitro digested finger millet food phenolic compounds and the percentage antioxidant activity of bioaccessible phenolic fraction. In this study, the TEAC was used to quantify the antioxidant capacity of compounds sequentially released as they would be in vivo during passage of digest through the stomach, the small and the large intestine. The results showed that gradual release of phenolic compounds with antioxidant activities during the digestion process was consistent for all foods examined. The TEAC of absorbable phenolic compounds after digestion of foods was in the order of Pittu $>$ Halape $>$ Thalapa $=$ Porridge $>$ Rotti.

The DRSA of bioaccessible fraction of in vitro digested food phenolics ranged from 1.7 to $10.3 \mu \mathrm{mol}$ trolox equivalent $/ \mathrm{g}(\mathrm{dm})$ for gastric phase and from 27.4 to $45.2 \mu \mathrm{mol}$ trolox equiv/g (dm) for intestinal phase (Table 3 ). The most effective food preparation method with high potential absorbable phenolics was the porridge (open boiled) and showed high DRSA. The present results showed that RP of bioaccessible phenolics of finger millet foods increased under in vitro digestion process (Table 3 ). The percentage antioxidant activity as measured by RP of absorbable fraction of phenolics of foods ranged from 42.3 to $83.6 \%$. The most effective food preparation method which showed high RP in potentially absorbable phenolics was steaming and was used to prepare Pittu.

The percentage FICA of absorbable phenolic compounds in in vitro digested finger millet foods ranged from 82 to $87 \%$ (Table 3 ). Generally, the absorbable phenolic compounds showed a higher percentage of FICA compared to those of other antioxidant activities studied in the present work. Furthermore, the results showed a high metal chelating effect at the small intestine after digestion of finger millet foods and this may have an effect on the intestinal iron absorption. The consumption of tea, red wine and other beverages rich in phenolic compounds inhibit the absorption of non-heme iron in the body (Samman et al., 2001). Dietary factors (phytic acid and tannic acid) inhibit iron absorption by their ability to prevent apical iron uptake, by chelating iron in the gastrointestinal lumen 
Table 3. Antioxidant activities ( $\mu \mathrm{mol}$ equiv/g of $\mathrm{dm}$ ) of bioaccessible and absorbable (\%) finger millet foods subjected to in vitro digestion and colonic fermentation

\begin{tabular}{|c|c|c|c|c|c|c|c|c|}
\hline & \multicolumn{2}{|c|}{ Aqueous extraction } & \multicolumn{2}{|c|}{$\begin{array}{l}\text { Static intestinal diges- } \\
\text { tion bioaccessiblility }\end{array}$} & \multicolumn{2}{|c|}{ Dynamic intestinal digestion } & \multirow{2}{*}{$\begin{array}{l}\text { Absorb- } \\
\text { able*** }\end{array}$} & \multirow{2}{*}{$\begin{array}{l}\text { Colonic fer- } \\
\text { mentation }\end{array}$} \\
\hline & Gastric & $\begin{array}{l}\text { Gastric + } \\
\text { Intestinal }\end{array}$ & Gastric & $\begin{array}{l}\text { Gastric + } \\
\text { Intestinal }\end{array}$ & Retentate* & Dialysate** & & \\
\hline \multicolumn{9}{|c|}{ Trolox equivalent antioxidant capacity (TEAC) $\mu \mathrm{mol}$ trolox equiv/g of $\mathrm{dm}$} \\
\hline Rotti & $1.6 \pm 0.0^{\mathrm{a}}$ & $7.8 \pm 1.7^{\mathrm{a}}$ & $21 \pm 2.0^{\mathrm{a}}$ & $39.0 \pm 2.4^{\mathrm{a}}$ & $23.0 \pm 0.3^{\mathrm{a}}$ & $11.3 \pm 1.8^{\mathrm{a}}$ & 29.0 & $5.14 \pm 1.2^{\mathrm{a}}$ \\
\hline Pittu & $1.3 \pm 0.3^{\mathrm{a}}$ & $3.4 \pm 0.4^{b}$ & $9.6 \pm 0.6^{b}$ & $53.5 \pm 2.7^{b}$ & $29.3 \pm 0.9^{b}$ & $25.6 \pm 2.3^{b}$ & 47.9 & $12.63 \pm 1.1^{b}$ \\
\hline Halape & $2.2 \pm 0.5^{b}$ & $15.0 \pm 1.3^{\mathrm{c}}$ & $5.6 \pm 0.0^{c}$ & $42.7 \pm 5.0^{\mathrm{a}}$ & $25.9 \pm 3.6^{b}$ & $18.3 \pm 3.2^{c}$ & 42.9 & $3.04 \pm 0.5^{c}$ \\
\hline Thalapa & $1.3 \pm 0.3^{a}$ & $11.8 \pm 1.0^{d}$ & $6.8 \pm 0.2^{c}$ & $42.4 \pm 0.3^{a}$ & $20.0 \pm 2.9^{a}$ & $17.5 \pm 3.3^{c}$ & 41.3 & $2.29 \pm 0.9^{c}$ \\
\hline Porridge & $9.0 \pm 0.4^{c}$ & $20.8 \pm 1.2^{\mathrm{e}}$ & $17.3 \pm 0.8^{\mathrm{d}}$ & $54.3 \pm 0.4^{b}$ & $32.7 \pm 3.7^{c}$ & $22.4 \pm 1.2^{b}$ & 41.3 & $4.86 \pm 1.1^{\mathrm{a}}$ \\
\hline \multicolumn{9}{|c|}{ 2,2-diphenyl-1-picrylhydrazyl (DPPH) radical scavenging ability(DRSA) $\mu$ mol trolox equiv/g of dm } \\
\hline Rotti & $1.4 \pm 0.0^{\mathrm{a}}$ & $8.4 \pm 0.2^{a}$ & $10.3 \pm 0.5^{a}$ & $27.4 \pm 1.3^{\mathrm{a}}$ & $16.0 \pm 3.2^{\mathrm{a}}$ & $7.2 \pm 0.1^{\mathrm{a}}$ & 26.3 & $6.07 \pm 0.4^{a}$ \\
\hline Pittu & $5.2 \pm 0.6^{b}$ & $5.4 \pm 0.1^{b}$ & $7.2 \pm 0.4^{b}$ & $30.2 \pm 1.0^{b}$ & $20.2 \pm 2.2^{b}$ & $10.8 \pm 3.0^{b}$ & 35.8 & $3.66 \pm 0.7^{b}$ \\
\hline Halape & $1.3 \pm 0.1^{a}$ & $6.9 \pm 0.3^{c}$ & $8.3 \pm 0.2^{c}$ & $39.7 \pm 1.3^{c}$ & $19.1 \pm 0.6^{b}$ & $17.8 \pm 0.8^{c}$ & 44.8 & $3.92 \pm 0.8^{b}$ \\
\hline Thalapa & $1.5 \pm 0.1^{\mathrm{a}}$ & $4.2 \pm 0.1^{d}$ & $1.7 \pm 0.2^{d}$ & $30.5 \pm 1.8^{b}$ & $13.3 \pm 0.1^{c}$ & $13.8 \pm 0.6^{d}$ & 45.2 & $5.36 \pm 3.3^{c}$ \\
\hline Porridge & $2.3 \pm 0.2^{c}$ & $7.2 \pm 0.1^{c}$ & $6.6 \pm 0.4^{b}$ & $45.2 \pm 1.2^{d}$ & $17.6 \pm 0.6^{d}$ & $25.5 \pm 2.5^{\mathrm{e}}$ & 56.4 & $3.01 \pm 0.6^{b}$ \\
\hline \multicolumn{9}{|c|}{ Reducing power (RP) $\mu \mathrm{mol}$ ascorbic acid equiv/g of $\mathrm{dm}$} \\
\hline Rotti & $14.1 \pm 0.7^{\mathrm{a}}$ & $22.2 \pm 0.2^{\mathrm{a}}$ & $31.8 \pm 1.7^{\mathrm{a}}$ & $36.6 \pm 3.0^{\mathrm{a}}$ & $18.1 \pm 0.1^{\mathrm{a}}$ & $15.5 \pm 1.2^{\mathrm{a}}$ & 42.3 & $22.9 \pm 5.2^{\mathrm{a}}$ \\
\hline Pittu & $9.7 \pm 1.0^{b}$ & $10.5 \pm 0.1^{b}$ & $17.4 \pm 1.9^{b}$ & $58.1 \pm 0.7^{b}$ & $7.5 \pm 0.7^{b}$ & $48.6 \pm 1.8^{b}$ & 83.6 & $17.3 \pm 1.0^{b}$ \\
\hline Halape & $5.1 \pm 0.7^{c}$ & $26.9 \pm 0.3^{c}$ & $17.2 \pm 1.8^{b}$ & $52.0 \pm 1.1^{c}$ & $19.3 \pm 1.6^{\mathrm{a}}$ & $31.8 \pm 2.8^{c}$ & 61.2 & $21.3 \pm 2.5^{\mathrm{a}}$ \\
\hline Thalapa & $12.3 \pm 0.2^{d}$ & $15.5 \pm 0.5^{d}$ & $13.3 \pm 0.2^{c}$ & $47.7 \pm 0.1^{d}$ & $16.2 \pm 1.4^{\mathrm{c}}$ & $28.6 \pm 2.9^{d}$ & 59.9 & $15.5 \pm 4.0^{b}$ \\
\hline Porridge & $17.7 \pm 0.7^{e}$ & $28.5 \pm 0.2^{\mathrm{e}}$ & $28.0 \pm 1.0^{d}$ & $53.8 \pm 1.9^{e}$ & $10.1 \pm 0.9^{d}$ & $46.3 \pm 1.1^{\mathrm{e}}$ & 79.4 & $21.3 \pm 3.3^{\mathrm{a}}$ \\
\hline \multicolumn{9}{|c|}{ Ferrous ion chelating ability (FICA) $\mu \mathrm{mol}$ EDTA equiv/g of $\mathrm{dm}$} \\
\hline Rotti & $56.2 \pm 1.2^{\mathrm{a}}$ & $102.3 \pm 1.2^{\mathrm{a}}$ & $129.5 \pm 3.2^{\mathrm{a}}$ & $187.5 \pm 0.5^{a}$ & $23.1 \pm 2.3^{\mathrm{a}}$ & $154.2 \pm 3.2^{\mathrm{a}}$ & 82.2 & $31.13 \pm 2.9^{\mathrm{a}}$ \\
\hline Pittu & $54.3 \pm 2.0^{\mathrm{a}}$ & $108.4 \pm 1.3^{\mathrm{a}}$ & $134.4 \pm 3.4^{b}$ & $175.2 \pm 0.4^{b}$ & $17.3 \pm 2.1^{\mathrm{b}}$ & $143.5 \pm 2.4^{\mathrm{b}}$ & 81.9 & $23.56 \pm 0.8^{b}$ \\
\hline Halape & $65.2 \pm 1.3^{b}$ & $105.3 \pm 1.2^{\mathrm{a}}$ & $120.6 \pm 3.0^{c}$ & $165.5 \pm 0.3^{c}$ & $14.5 \pm 1.4^{c}$ & $140.5 \pm 2.1^{\mathrm{b}}$ & 84.8 & $24.24 \pm 7.6^{b}$ \\
\hline Thalapa & $45.1 \pm 1.4^{c}$ & $95.2 \pm 1.3^{b}$ & $101.2 \pm 2.1^{d}$ & $190.2 \pm 0.1^{d}$ & $23.1 \pm 1.0^{\mathrm{a}}$ & $165.2 \pm 2.2^{c}$ & 86.8 & $24.68 \pm 4.7^{b}$ \\
\hline Porridge & $40.3 \pm 1.0^{c}$ & $90.2 \pm 0.8^{b}$ & $110.1 \pm 2.1^{d}$ & $183.2 \pm 0.4^{d}$ & $20.4 \pm 1.5^{a}$ & $153.4 \pm 1.2^{d}$ & 83.7 & $31.13 \pm 3.9^{a}$ \\
\hline
\end{tabular}

*Retentate, non-dialized fraction after intestinal digestion and represent unabsorbed compounds; ** Dialysate, dialyzed fraction after intestinal digesation and represent absorbed compounds; *** Percentage (\%) antioxidant activity of absorbable phenolic compounds; $\mathrm{dm}$, dry matter, The same letters in each column are not significantly different (>0.05).

and limiting access to the apical surface of enterocytes (Kim et al., 2008).

\subsection{Bioaccessibility of phenolics of food residues subjected to colonic fermentation}

Table 2 presents phenolic contents of finger millet food residues subjected to simulated in vitro colonic fermentation. Phenolic compounds bound to the matrix of undigested food components pass into the large intestine and phenolic acids are released by colonic microflora (Deprez et al., 2000; Rechner et al., 2002; Hervert and Goni, 2011). In this study insoluble bound phenolic compounds which were retained in the food residues are released during microbial fermentation. The TPC of food residues ranged from 15.8 to $26.8 \mu \mathrm{mol}$ of $\mathrm{FAE} / \mathrm{g} \mathrm{dm}$ after microbial fermentation for $24 \mathrm{~h}$. Further, residues of Pittu (steamed) had 1.6 times higher TPC than that of Thalapa (open boiled) which showed the low- est. The results suggest that cooking method influences the release of phenolics after colonic fermentation. In agreement, other studies have shown that microbial fermentation in the colon releases phytochemicals bound to the fibre matrix of cereal grains and increases the bioavailability after fermentation (Saura-Calixto et al, 2007; Hervert and Goni, 2011).

TPC may include polyphenols released from the food matrix by the action of bacterial enzymes during colonic fermentation (Hervert and Goni, 2011). The fermentation products of polyphenols such as phenylacetic, phenylpropionic and phenylvaleric acids are produced by the metabolism of condensed tannins. Previous studies have shown that phenolic compounds and their metabolic products released upon microbial fermentation can be absorbed into the blood stream through the colonic epithelium (Gonthier et al., 2003; Williamson and Manach, 2005). Furthermore, unabsorbed phenolic compounds have the ability to counteract the effects of dietary prooxidants in the colon produced during colonic bacterial metabolism (Scalbert et al., 2002). The TFC of 
food residues after $24 \mathrm{~h}$ colonic fermentation ranged from 2.01 to $5.64 \mu \mathrm{mol}$ of $\mathrm{CE} / \mathrm{g}(\mathrm{dm})$ (Table 2). Flavonoid compounds remaining in the residues after intestinal digestion undergo microbial fermentation. Previous studies have reported that uningested dietary flavonoid compounds pass to the large intestine and undergo colonic biotransformation by the enzymes of the colonic microflora to simple phenolic compounds (Rechner et al., 2002).

\subsection{Antioxidant activities of bioaccessible phenolics of food residues subjected to colonic fermentation}

The TEAC, DRSA, RP and FICA values of phenolics released from colonic fermented food residues are presented in Table 3. The results show that finger millet food residues released phenolic compounds with potential antioxidant activities in the colon. It is noted that the highest value of each antioxidant activity assay varied depending on the food preparation method. However, Rotti, the unfermented flat bread, showed the highest DRSA, RP and FICA, among other foods (Table 3).

\section{Conclusions}

Different cooking methods affect the phenolic contents and antioxidant activities of finger millet foods. The release of phenolic compounds increased stepwise from gastric to intestinal phase for all finger millet foods and their bioaccessibility and potential absorption depended on different food preparation methods. The released phenolic compounds and their antioxidant activities at each phase of digestion of finger millet showed the potential ability of protecting human gastrointestinal tract from conditions related to oxidative stress. Generally, finger millet thin and thick porridges prepared by open boiling showed more absorbable phenolic compounds and high potential to provide postprandial antioxidant activities compared to other food preparation methods used. In vivo human clinical studies are warranted to investigate the ability of finger millet foods to prevent or reduce the occurrence of oxidative stress related NCDs.

\section{Acknowledgments}

This research was supported by the National Research Council of Sri Lanka (NRC 12-096) through a research grant to AC.

\section{References}

Chandrasekara, A., and Shahidi, F. (2010). Content of insoluble bound phenolics in millets and their contribution to antioxidant capacity. J. Agric. Food Chem. 58(11): 6706-6714.

Chandrasekara, A., and Shahidi, F. (2011). Determination of antioxidant activity in free and hydrolyzed fractions of millet grains and characterization of their phenolic profiles by HPLC-DAD-ESI-MS ${ }^{n}$. J. Functional Foods 3(3): 144-158.

Chandrasekara, A., and Shahidi, F. (2012). Bioaccessibility and antioxidant potential of millet grain phenolics as affected by simulated in vitro digestion and microbial fermentation. J. Functional Foods 4(1): 226-237.

Chandrasekara, A., Naczk, M., and Shahidi, F. (2012). Effect of processing on the antioxidant activity of millet grains. Food Chem. 133(1): 1-9.

Deprez, S., Brezillon, C., Rabot, S., Philippe, C., Mila, I., Lapierre, C., and Scalbert, A. (2000). Polymeric proanthocyanidins are catabolized by human colonic microflora into low molecular weight phenolic acids.
J. Nutr. 130(11): 2733-2738.

Dewanto, V., Wu, X., and Liu, H. (2002). Processed sweet corn has higher antioxidant activity. J. Agric. Food Chem. 50(17): 4959-4964.

Duh, P.D., Yen, G.C., Yen, W.J., and Chang, L.W. (2001). Antioxidant effects of water extracts from barley (Hordeum vulgare L.) prepared under different roasting temperatures. J. Agric. Food Chem. 49(3): 1455-1463.

Duodu, K.G. (2014). Effect of processing on phenolic phytochemicals in cereals and legumes. Cereal Foods World 59(2): 64-70.

Fasai, O., and Ilayo, S. (2009). Proximate antinutritional factors and functional properties of processed pearl millet (Pennisetum glucum). J. Food Technol. 7(3): 92-97.

Gonthier, M.P., Cheynier, V., Donovan, J., Manach, C., Morand, C., and Mila, I. (2003). Microbial aromatic acid metabolites formed in the gut account for major fraction of the polyphenols excreted in urine of rats fed red wine polyphenols. J. Nutr. 133(2): 461-467.

Hervert, H.D., and Goni, I. (2011). Dietary polyphenols and human gut microbiota a review. Food Rev. Inte. 27(2): 154-169.

Hithamini, G., and Sirinivasan, K. (2014). Effect of domestic processing on the polyphenol content and bioaccessibility in finger millet (Eleusine coracana) and pearl millet (Pennisetum glaucum). Food Chem. 164(1): 55-62.

Infante, J.A.G., Guzmen, N.E.R., Laredo, R.F.G., and Alonso, J.P. (2010) Effect of processing on the antioxidant properties of extracts from Mexican barley (Hordeum vulgare) cultivar. Food Chem. 119(3): 903-906.

Jenner, A.M., Rafter, J., and Halliwell, B. (2005). Human fecal water content of phenolics: The extent of colonic exposure to aromatic compounds. Free Rad. Biol. Med. 38(6): 763-772.

Kim, E., Ham, S., Shigenaga, M.K., and Han, O. (2008). Bioactive dietary polyphenolic compounds reduce non heme iron transport across human intestinal cell monolayers. J. Nutr. 138(9): 1647-1651.

Konishi, Y., Zhao, Z., and Shimizu, M. (2006). Phenolic acids are absorbed from the rat stomach with different absorption rates. J. Agric. Food Chem. 54(7): 7539-7543.

Kumari, D., Madhujith, T., and Chandrasekara, A. (2017). Comparison of phenolic content and antioxidant activities of millet varieties grown in different locations in Sri Lanka. Food Sci. Nutr. 5(3): 474-485.

Lee, W.Y., Emmy, H.K.I., Abbe Maleyki, M.J., and Amin, I. (2007). Antioxidant capacity and phenolic content of selected commercially available cruciferous vegetables. Malaysian J. Nutr. 13(1): 71-80.

Marambe, H.K., Shand, P.J., and Wanasundara, J.P.D. (2011). Release of Angiotensin I-converting enzyme inhibitory peptides from flaxseed (Linum usitassimum L.) protein under simulated gastrointestinal digestion. J. Agric. Food Chem. 59(17): 9596-9604.

McKeown, N.M. (2002). Whole grain intake is favorably associated with metabolic risk factors for type 2 diabetes and cardiovascular disease in the Framingham Offspring Study. Am. J. Clin. Nutr. 76(2): 390-398.

Meyer, K.A., Kushi, L.H., Jacobs, D.R.J., Slavin, J., Sellers, T.A., and Folsom, A.R. (2000). Carbohydrates, dietary fiber, and incident type 2 diabetes in older women. Am. J. Clin. Nutr. 71(4): 921-930.

Minaxi, R., Prajapati, V.P., Tarak, P., and Rema, S. (2013). Effect of in bioprocessing on antioxidant activity of selected cereals. Asian J. Plant Sci. Res. 3(2): 66-72.

Passamonti, S., Vrhovsek, U., Vanzo, A., and Mattivi, F. (2003). The stomach as a site for anthocyanins absorption from food. Fed. Eur. Biochem. Soc. Lett. 544(1-3): 210-213.

Pradeep, P.M., and Yadahally, N.S. (2015). Impact of processing on the phenolic profiles of small millets: evaluation of their antioxidant and enzyme inhibitory properties associated with hyperglyceamia. Food Chem. 169(15): 455-463.

Pradeep, S.R., and Guha, M. (2011). Effect of processing methods on the nutraceutical and antioxidant properties of little millet (Panicum sumatrense) extracts. Food Chem. 126(4): 1643-1647.

Pushparaj, F.S., and Urooj, A. (2014). Antioxidant activity in two pearl millet (Pennisetum typhoideum) cultivars as influenced by processing. Antioxidants 3(1): 55-66.

Ragaee, S., Seetharaman, K., and Abdel-Aal, E.S.M. (2014). Impact of milling and thermal processing on phenolic compounds in cereal grains. Critic Rev. Food Sci. Nutr. 54(7): 837-849.

Rechner, A., Kuhnle, G., Bremner, P., Hubbard, G., Moore, K., and Rice-Ev- 
ans, C. (2002). The metabolic fate of dietary polyphenols in human. Free Radical Biol. Med. 33(2): 220-235.

Samman, S., Sandstrom, B., Toft, M.B., Bukhave, K., Jensen, M., Sorensen, S.S., and Hansen, M. (2001). Green tea or rosemary extract added to foods reduces nonheme-iron absorption. Am. J. Clin. Nutr. 73(3): 607-612.

Saura-Calixto, F., Serrano, J., and Goni, I. (2007). Intake and bioaccessibility of total polyphenols in a whole diet. Food Chem. 101(2): 492-501.

Scalbert, A., Morand, C., Manach, C., and Remesy, C. (2002). Absorption and metabolism of polyphenols in the gut and impact on health. $\mathrm{Bi}$ omed. Pharmacother 56(6): 276-282.

Shahidi, F., and Chandrasekara, A. (2010). Hydroxycinnamates and their in vitro and in vivo antioxidant activities. Phytochem. Rev. 9: 147-170.

Shahidi, F., and Chandrasekara, A. (2013). Millet grain phenolics and their role in disease risk reduction and health promotion: A review. J. Funct. Foods 5: 570-581.

Shahidi, F., and Chandrasekara, A. (2014). Processing of millet grains and effects on non-nutrient antioxidant compounds. Processing and im- pact on active components in foods. In: Preedy, V.R. (Ed.). Elsevie Inc., UK, pp. 345-392.

Shahidi, F., and Peng, H. (2018). Bioaccibility and bioavailability of phenolic compounds. J Food Bioact. 4: 11-68.

Shahidi, F., Zhong, Y., and Chandrasekara, A. (2012). Antioxidants and human health. Cereals and Pulses: Nutraceutical Properties \& Health Benefits. In: Yu, L.L., Taso, R, and Shahidi, F (Ed.). John Wiley \& Sons Inc, UK, pp. 273-308.

Swieca, M., Gawlik-Dziki, U., Dziki, D., Baraniak, B., and Czyż, J. (2013). Influence of protein-flavonoid interactions on protein digestibility in vitro and the antioxidant quality of bread enriched with onion skin. Food Chem. 141(1): 451-458.

Williamson, G., and Manach, C. (2005). Bioavailability and bioefficacy of polyphenols in humans. II. Review of 93 intervention studies. Am. J. Clin. Nutr. 81(1): 243S-255S.

Yeo, J., and Shahidi, F. (2015). Critical evaluation of the changes in the ratio of insoluble bound to soluble phenolics on antioxidant activity of lentils during germination. J. Agric. Food Chem. 63(2): 379-381. 